\title{
Mindel- und rißeiszeitliche Endmoränen des Illervorlandgletschers
}

\author{
Von Gunnar Glückert, Turku
}

Mit 4 Abbildungen und 1 Tafel

\begin{abstract}
$\mathrm{Z}$ us a mmenf assung. Die mindel- und rißeiszeitlichen Eisrandlagen im Altmoränengebiet des Illervorlandgletschers wurden mit morphologischen und stratigraphischen Hilfsmitteln kartiert und dabei zum ersten Mal voneinander getrennt und näher beschrieben. Der äußere schmale Gürtel der Mindelmoränen und die breitere Zone der Rißmoränen liegen auf hohen günz- und mindelzeitlichen Schotterriedeln zu beiden Seiten der tief eingeschnittenen Erosionstäler zwischen Memmingen und Kaufbeuren.

$\mathrm{S} \mathrm{u} \mathrm{m} \mathrm{m} \mathrm{a} \mathrm{r} \mathrm{y.} \mathrm{The} \mathrm{pre-Würm} \mathrm{end} \mathrm{moraines} \mathrm{of} \mathrm{the} \mathrm{Mindel} \mathrm{and} \mathrm{Riss} \mathrm{Glaciations} \mathrm{of} \mathrm{the} \mathrm{Alpine}$ Iller piedmont Glacier, lying on the northern foreland of the Alps, southern West Germany, have been studied with morphological and stratigraphical methods by the author and described in this paper. The prominent Mindel and Riss end moraines, which are situated on remnants of highlying Günz and Mindel gravel plains, have not previously been investigated in detail and distinguished from each other.
\end{abstract}

\section{Einführung}

Seit den Aufnahmen von Penck \& BrǘcKner (1909) sowie von Eberl (1930) ist die Iller-Lech-Platte im Allgäu immer wieder in der Eiszeitenforschung hervorgehoben worden. In den vielen Arbeiten spielt insbesondere der Memminger Raum eine wichtige Rolle. PENCK hat mit den vier Feldern von Memmingen zum ersten Mal den Nachweis für eine Viergliedrigkeit des Eiszeitalters erbracht. Er unterteilt die vier treppenförmig übereinander liegenden Schotterfelder südlich Memmingen in das Memminger Feld (die Niederterrasse der jungpleistozänen Würmeiszeit), das Hitzenhofer Feld (die Hochterrasse der mittelpleistozänen Rißvereisung), das Grönenbacher Feld (der jüngere Deckenschotter der altpleistozänen Mindeleiszeit) und das Hochfeld (der ältere Deckenschotter der altpleistozänen Günzeiszeit) PencK \& Brückner (1909, 28-30). Eberl (1930) hat die Eiszeitenfolge im Gebiet des Lech- und Illergletschers um eine fünfte Glazialzeit, die Donaukaltzeit erweitert. Die Mindelvereisung war die größte im Gebiet des Illervorlandgletschers (PeNCK \& BRÜCKNer 1909, 177), im westlichen Rheingletschergebiet hatte dagegen die Rißvereisung die größte Ausdehnung (Graul 1968).

Schottervorkommen der prägünzzeitlichen Donauvereisung, die dem Ältestpleistozän zugerechnet wird, lassen sich im Bereich der Staudenplatte bei Augsburg, und im mittleren und nördlichen Teil der Iller-Lech-Platte, u. a. bei Aindling, Arlesried, Hochfirst, Staufenberg und Stoffersberg nachweisen (z. B. Eberl 1930, Schaefer 1953 a und SinN 1971, 1972).

Zuletzt befaßte sich vor allem SINN (1972) mit den mittel- und altpleistozänen Schotterfeldern im mittleren und südlichen Illergletschervorland. Er behandelt dabei auch kurz die mindel- und rißeiszeitlichen Eisrandlagen.

Außerdem haben Schaefer (1951, 1953 b, 1973) und Graul (1953) in ihren Arbeiten die Altmoränen und Schotter im Illergletschergebiet beschrieben. German (1960, 1962) hat Untersuchungen im Bereich der würmeiszeitlichen Lech-, Iller- und Rheinvorlandgletscher durchgeführt. Im Süden der Iller-Rißplatte haben sich Graul (1962), EICHLER (1970 a, b) und MADER (1971) mit dem präwürmzeitlichen Pleistozän im östlichen Rheingletschergebiet befaßt (vgl. auch GLÜCKERT 1974). 
Die Geländeuntersuchung zur vorliegenden Arbeit wurde im Juni 1973 durchgeführt. Dieses Vorhaben konnte Dank der Unterstützung der Alexander von Humboldt-Stiftung unternommen werden. Dem Vorstand des Geologischen Instituts der Technischen Universität zu München, Herrn Prof. Dr. P. Schmidt-Thomé, dankt der Verfasser bestens für die Befürwortung des Stipendiums. Besonderen Dank schuldet der Verfasser Herrn Dr. H. Jerz, Bayerisches Geologisches Landesamt, München, der diese Arbeit anregte und die Zeit zu mehreren gemeinsamen Geländebegehungen aufbrachte.

\section{Arbeitsgebiet}

Das erforschte Gebiet hat eine West-Ost-Erstreckung von etwa $35 \mathrm{~km}$ und eine NordSüd-Breite von $13 \mathrm{~km}$ und umfaßt das Altmoränengebiet des Illervorlandgletschers zwischen der Iller südwestlich Grönenbach und der Wertach bei Kaufbeuren (Abb. 1). Der Südteil reicht noch in das äußere Jungmoränengebiet hinein, während der nördliche Teil längs der Linie Grönenbach-Ottobeuren-Markt Rettenbach-nördlich Kaufbeuren an die Deckenschotter angrenzt. Das Untersuchungsgebiet liegt zwischen 700—900 $\mathrm{m}$ ü NN. Das Ziel dieser Arbeit war, die mindel- und rißeiszeitlichen Eisrandlagen im Altmoränengebiet des Illervorlandgletschers durch morphologische und stratigraphische Hilfsmittel zu kartieren und dabei die verschieden alten Endmoränen voneinander zu trennen.

Die hier untersuchten alt- und mittelpleistozänen Endmoränen sind im Illerlobusbereich bisher noch nicht genauer kartiert und beschrieben worden. Die Altmoränen wurden auch von Penck (1909), Eberl (1930), Schaefer (1953 b) und Sinn (1972) nur in groben Zügen behandelt.

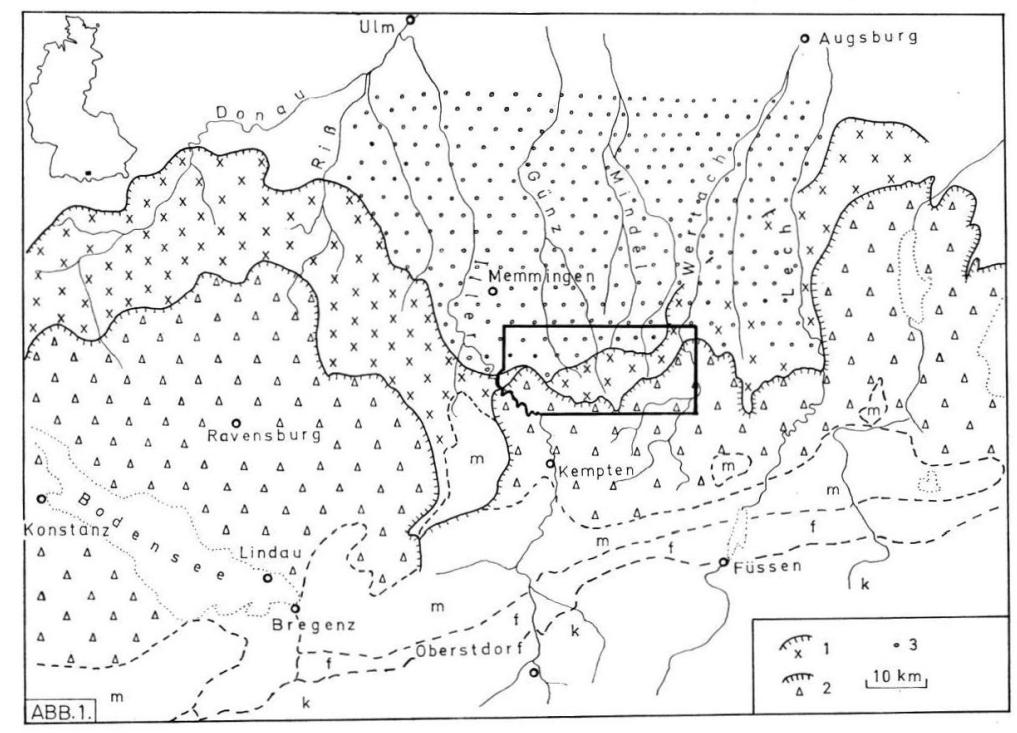

Abb. 1. Geologische Ubersichtskarte des westlichen Alpenvorlandes. Ausschnitt aus der Geologischen Karte von Bayern, 1:500 000, 1964. Das Untersuchungsgebiet ist eingerahmt. 1. Grenze der älteren Moränen (Riß, Mindel), 2. Grenze der Jungmoränen, 3. Pleistozäne Schotter, m Molasse, f Flysch, k Kalkalpin.

Aufgrund dieser Arbeit wurde die Karte der Eisrandlagen des Illervorlandgletschers zusammengestellt (Tafel I). Diese Karte zeigt gegenüber der Geologischen Übersichtskarte von Baden-Württemberg $(1: 200000$, Blatt 4) einige Verbesserungen und gegenüber 
den Aufnahmen von Eberl (1930), Schaefer (1953 b) und Sinn (1972) die Unterscheidung der mindel- und rißeiszeitlichen Gletscherrandlagen. Auf der Geologischen Übersichtskarte von Baden-Württemberg $(1: 200$ 000) ist das Gebiet der Rißmoränen von den älteren Schottern und Moränen getrennt. Auf der Geologischen Karte von Bayern (1:500000) sind diese Randlagen nicht voneinander unterschieden, sondern nur als „Ältere Moränen“ (R) angegeben.

\section{Eisrandlagen}

Bereits EBERL (1930) führte in groben Zügen eine Gliederung der Altmoränen im Illergletscherlobus durch. Vom Verfasser wurde der Versuch unternommen, die alt- und mittelpleistozänen Eisrandlagen in diesem Gebiet auf geomorphologischer Basis genauer aufzunehmen und etwas feiner zu differenzieren.

Die Haupteisströme, welche die Lage und Form der Endmoränengürtel im Arbeitsgebiet bestimmen, werden als Illertal- und Günztalzunge des Illervorlandgletschers bezeichnet. Im Jungpleistozän spaltete sich der Illergletscher in die Kemptener (Dietmannsrieder) Hauptzunge und die kleinere Günztalzunge. Im Osten grenzt der Wertachgletscher an den Illerlobus. Das untersuchte Gebiet liegt im Bereich der würmzeitlichen GünztalNebenzunge zwischen der Wertachzunge im Osten und der Kemptener Hauptzunge im Westen, wobei letztere mit ihrem Ostteil noch in die Kartierung einbezogen wurde (Tafel I).

Die Hauptvorkommen der älteren pleistozänen Ablagerungen im nördlichen Alpenvorland sind auf das Gebiet zwischen Lech und Iller beschränkt. Für die Gliederung der Endmoränen auf der Lech-Iller-Platte bietet die breite Randzone der Vereisungen relativ günstige Voraussetzungen. In der Grundmoränenlandschaft, wo mehrere glaziale Serien übereinander liegen, sind die Verhältnisse wesentlich ungünstiger. Nur die Ablagerungen der jüngsten Kaltzeit sind dort frisch und deutlich erhalten. Die Bildungen der vorhergehenden Eiszeiten sind im allgemeinen um so mehr ausgeräumt, umgelagert und verdeckt, je älter sie sind. Zu den Ablagerungen des Alt- und Mittelpleistozäns gesellt sich noch die besondere Schwierigkeit, zwischen erhaltenen Resten die richtige Beziehung herauszufinden.

Die präwürmzeitlichen Endmoränen des Illergletschers liegen hoch oben auf den Schotterfeldern und sind verhältnismäßig eng nebeneinander angeordnet. Im westlichen Teil des Arbeitsraumes ist das Altmoränengebiet so schmal, daß zwischen den Mindelschottern und den Jungmoränen, innerhalb von zwei Kilometern, die Mindel- und Rißrandlagen eng zusammengedrängt sind. Unmittelbar östlich der heutigen Iller liegen diese verschiedenaltrigen Randlagen ganz dicht bei- oder sogar aufeinander. Weiter östlich, hinter der Westlichen Günz, sind die Altmoränenkränze breiter und etwas weiter gestaffelt.

Die Mindel- und Rißmoränen sind im Untersuchungsraum selten aufgeschlossen. Ihre Morphologie ist dafür eindeutig. Die flachen, abgerundeten Formen der Altmoränen der Rißzeit sind meist deutlich zu erkennen, wenn auch nicht ganz so gut wie die frischen Formen der würmeiszeitlichen Moränen. Die mindeleiszeitlichen Endmoränen liegen auf den hochgelegenen, älteren Schotterflächen und bilden sehr flachgewölbte, in einzelne Kuppen zerschnittene, quer zur Eisbewegungsrichtung liegende Rücken. Ihre Formen sind im allgemeinen flacher und niedriger als die der meist bedeutend größeren und höheren Rißmoränen.

Im Gegensatz zu den Jungmoränen sind die flacheren Mindel- und Rißmoränen frei von frischen Wallformen und Söllen. Das präwürmzeitliche Moränenmaterial ist außerdem ziemlich tief ( 2 bis über $3 \mathrm{~m}$ ) verwittert, während die Verwitterungsschicht der Jungmoränen nur bis höchstens $1 \mathrm{~m}$ mächtig ist. 
Im Verlauf der alten Eisrandlagen kann man die Umrisse einiger präwürmzeitlicher Gletscherloben erkennen (Abb. 2).

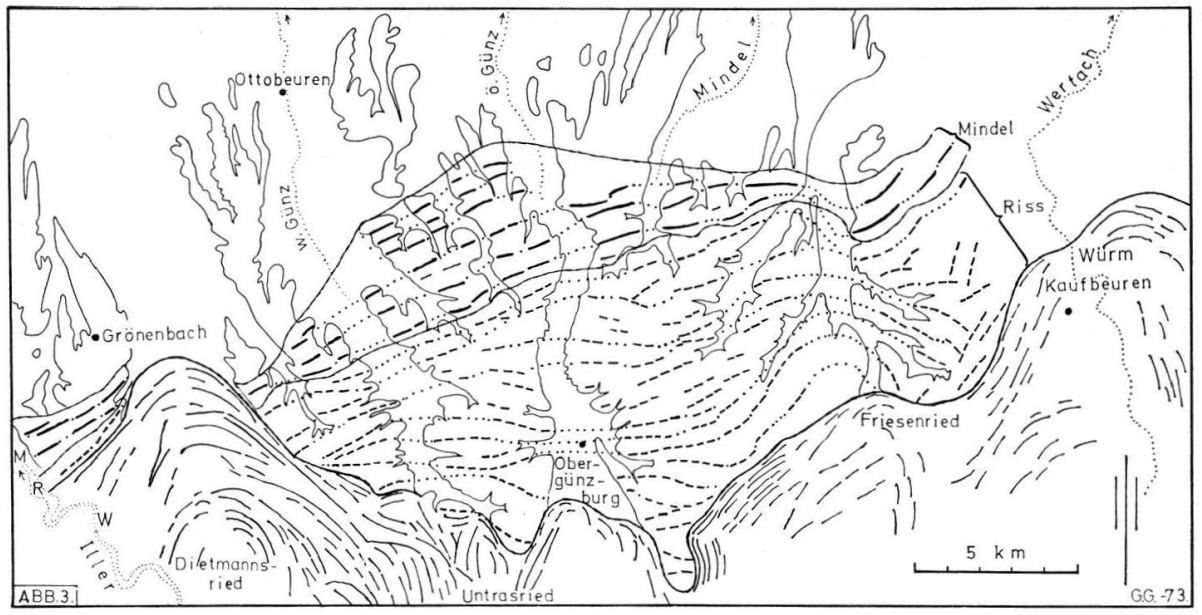

Abb. 2. Rekonstruktion der Mindel-, Riß- und Würmeisrandlagen im Bereich des Illervorlandgletschers nach den Endmoränenbögen.

Vielfach lassen sich bereits durch den verschieden gerichteten Verlauf der alten glazialen Entwässerungsrinnen die Mindel- und Rißmoränen voneinander trennen. Der mindeleiszeitliche Endmoränengürtel ist während der Rißeiszeit durch die zentrifugal abziehenden Schmelzwässer in zahlreiche Wallreste zerschnitten worden, die heute durch tief eingeschnittene Erosionstäler voneinander getrennt sind. Während des Rückzuges des Rißgletschers liefen die Schmelzwässer meistens, durch die hohen querliegenden Moränenwälle behindert, zu beiden Seiten in peripheren Rinnen ab.

Die Schotter der Günzvereisung sind, die periglazial-fluviatilen Ottobeurer Schotter ausgenommen, als die ältesten Glazialablagerungen im Arbeitsgebiet anzusehen. Es wird angenommen, daß die Günzmoränen mindestens die Ausdehnung der Würmmoränen erreicht haben. Nach EICHLER (1970 b) reichte der günzzeitliche Gletscherrand im östlichen Rheingletschergebiet zwischen die Vereisungsgrenzen von Riß und Mindel. Alle den Günzschottern zugehörigen Moränen sind im Illergebiet durch jüngere Vergletscherungen ausgeräumt worden.

Im Bereich der Kemptener und der Günztal-Eiszungen hat sich der würmeiszeitliche Illervorlandgletscher im Arbeitsgebiet in folgende separate Gletscherzungen aufgespalten: die Dietmannsrieder, die Untrasrieder und die Obergünzburger Zunge. Dem östlich benachbarten Wertachgletscher gehören die Friesenrieder und die Kaufbeurener Zunge an. Die Eisrandlagen dieser jungpleistozänen Gletscherzungen werden im Rahmen dieses Themas nicht näher behandelt.

\section{Randlagen der Mindeleiszeit}

Die weiteste Ausdehnung gegen Norden im Bereich des Illervorlandgletschers erreichte die altpleistozäne Mindelvereisung. Die Randlagen der jüngeren Riß- und Würmeiszeiten sind bis zu einigen Kilometern hinter dem mindeleiszeitlichen Maximalstand zurückgeblieben. Die nördlichsten Vorkommen der mindeleiszeitlichen Moränen befinden sich bei Bruderhof und Linden nördlich Dingisweiler, Neuenried (Holzheuer Höhe), Reichartsried 
südlich Bayersried und zu beiden Seiten des Mühlbachtales bei Eggenthal. In mehreren Aufschlüssen sind dort auf Günz- oder Mindel-Schotter mindeleiszeitliche Moränen zu erkennen. Die Grenze der Mindelmoränen liegt etwas nördlich der äußersten morphologisch erkennbaren Endmoränen. Der Rand der Mindelvereisung ist in der Karte (Tafel I) angegeben.

Die Form und Größe der mindeleiszeitlichen Endmoränen wechseln stark. Meist sind es runde oder längliche, flachgewölbte Kuppen, die sich 2 bis über 20 m über der Schotterfläche erheben.

An der Iller bildet die äußerste Mindelmoräne einen mächtigen Wall (790 m) bei den Höfen Brandholz und Manneberg (vgl. Penck \& BRüCKner 1909, 37, EBerl 1930, 277 und Schaefer 1951, 105). Die festverbackene Blockmoräne liegt als 30-40 m mächtige Decke auf dem Tertiär (OSM) und ist deutlich am benachbarten Illersteilhang aufgeschlossen. (Tafel I).

Die äußerste Mindelrandlage bei Brandholz-Manneberg setzt sich bei Vorm Wald nach NE fort. Bei Waldschenke liegt noch ein kleiner mindeleiszeitlicher Moränenwall im Grönenbacher Wald verborgen. Gleich nördlich davon stellt ein Übergangskegel die Verbindung her zu den Mindelschottern des Grönenbacher Feldes. Die flachgewölbten Moränenrücken bei Greit zu beiden Seiten eines tiefeingeschnittenen Schmelzwassertales des Rißgletschers werden ebenfalls der Mindeleiszeit zugeordnet. Die Brandholz-MannebergMoräne bildet den westlichsten Randbereich des mindeleiszeitlichen Illergletschers im Arbeitsgebiet.

Weitere mindeleiszeitliche Endmoränenreste sind auf den günzeiszeitlichen Schotterriedeln östlich des Memminger Trockentales erhalten. Auf dem Falkener Riedel östlich Ittelsburg liegt südlich Vorder- und Hinter-Gsäng die Grenze der Mindelmoräne mit dem äußersten Moränenwall.

Der lange Böhener Riedel erstreckt sich von östlich Schrattenbach im Süden bis Ottobeuren im Norden. Auf dieser verzweigten günzzeitlichen Hochfläche sind südlich Böhen drei bis vier Reste von Mindelrandlagen bei Berg, Lampolz, Unterwarlins bzw. Rechberg eng nebeneinander angeordnet. Der Doppelwall $(835 \mathrm{~m})$ zwischen Lampolz und Unterwarlins ist der markanteste; er erhebt sich $30 \mathrm{~m}$ über dem Mindel-Übergangskegel südlich Böhen. Die Mindel-Riß-Grenze liegt zwischen den Dörfern Unter- und Oberwarlins, wo die Rißschmelzwässer zu beiden Seiten tiefe Erosionstäler eingeschnitten haben.

Während im Dorf Böhen noch ein moränennaher Günzschotter zu Tage tritt (Aufschlüsse 1 und 2, Tafel I), ist bei Berg, südlich Böhen, die eisrandnahe kristallinarme Mindel-Schottermoräne aufgeschlossen (3). Spuren von etwa $5 \mathrm{~m}$ tiefen geologischen Orgeln sind an der Aufschlußwand zu erkennen. Die Mindelmoräne ist außerdem in den Aufschlüssen bei Rechberg und Rumpfer südöstlich Böhen deutlich zu sehen.

Am Nordende des Rechbergs liegt unter der Mindelmoräne ein grobkörniger, schlecht geschichteter moränennaher Schotter mit einer Unterkante bei $787 \mathrm{~m}$ auf dem an der Sohle der Kiesgrube zu Tage tretenden Tertiärsand (4). Die gleiche Abfolge wird auch in der Kiesgrube bei Rumpfer angetroffen (5). Unter der grobblockigen Moräne ist eine moränennahe Nagelfluh zu erkennen. Über dem Tertiär liegt noch ein loser, vorwiegend feinkörniger Periglazialschotter mit hohem Kristallingehalt (bis zu 16\%), der zum Teil aus umgelagertem Molasse-Material besteht (vgl. SinN 1972, 86-87).

Die entsprechenden Mindelmoränen lassen sich morphologisch und stratigraphisch in drei hintereinander angeordneten Wällen bei Günzegg und Bibelsberg auf den Höhen östlich der Westlichen Günz weiterverfolgen. Bei Günzegg ist im Aufschluß am Wegrande eine verbackene Mindelmoräne auf einer verfestigten Mindel-Schottermoräne aufgeschlossen (6). Darunter ist noch eine dünne Schicht eines altpleistozänen periglazial-fluviatilen, 
dolomitfreien, feinkörnigen Schotter mit viel Kristallin $(10 \%)$ erhalten (vgl. SinN 1972, 87-88). Die Grenze zu den bedeutend höheren und größeren Rißendmoränen bei Hinterschmolholz liegt etwa $500 \mathrm{~m}$ südlich von den innersten Mindelrandlagen bei Günzegg und Osterberg.

In der Gegend von Ollarzried, zwischen Kuisler (äußerste Rißendmoräne) und Bühl, ist die Zone der Mindelmoränen deutlich breiter $(4 \mathrm{~km})$ als bei Böhen, indem dort 7-8 hintereinander gestaffelte Mindelrandlagen ausgebildet sind. Bei Bibelsberg-Bühl, mit dem äußersten mindelzeitlichen Doppelrücken, ist die Randlage am Weg aufgeschlossen (7). Nördlich Ollarzried lassen sich die äußersten flachen Mindelwälle bei Hahnenbühl-Rettenmühle feststellen.

Bei Vogelsang ist ein verfestigter moränennaher Mindelschotter mit gerundeten Steinen bis $15 \mathrm{~cm}$ Durchmesser und Resten von geologischen Orgeln aufgeschlossen (8). Der Rücken bei Bremberg bildet die innerste Mindelmoräne in diesem Gebiet. An seinem Unterhang ist in der Kiesgrube bei Moosmühle ein verfestigter Mindelschotter mit Orgelresten von z. T. lockerem Rißschotter überdeckt (9).

Die Mindelrandlagen in der Gegend von Ollarzried sind durch tiefe Abflußtäler der zentrifugal abziehenden rißeiszeitlichen Schmelzwässer in zahlreiche Wallreste zerschnitten. Die Höhe bei Oberhaslach nördlich Bibelsberg scheint schon zu den günzeiszeitlichen Schotterablagerungen zu gehören und liegt außerhalb des altpleistozänen Endmoränengürtels (vgl. SinN 1972, 71-72).

Auf den Höhen westlich des Ostlichen Günztales ist bei Dingisweiler-Oberweiler mit einer $4 \mathrm{~km}$ breiten mindeleiszeitlichen Moränenzone eine ähnliche Abfolge wie bei Bibelsberg zu erkennen. Die äußerste Grenze des Mindelgletschers kann in den flachen Höhenresten bei Grub und Bruderhof nördlich Dingisweiler aufgespürt werden. Dort ist die Mindelmoräne nur ganz flach auf die Schotterfelder aufgeschoben worden, weshalb die Grenze der Moränendecke zu den angrenzenden Mindelschottern nicht genau festgelegt werden kann (10). Bei Linden nördlich Bruderhof war in einem frischen Leitungsgraben noch die Mindelmoräne mit kantigen Steinen zu sehen (11).

Die $10-20 \mathrm{~m}$ hohen Wälle bei Dingisweiler $(787 \mathrm{~m})$ und westlich Oberweiler (826) bilden die markantesten mindeleiszeitlichen Gletscherrandlagen zwischen Ollarzried und Ronsberg. Die rißeiszeitlichen Schmelzwässer haben den inneren Gürtel der Mindelrandlagen bei Oberweiler mit einem tiefen Erosionstal in zwei Teile zerschnitten. Zwischen Stein und Unterweiler ist die Grenze zwischen Mindelmoräne und -schotter sowohl stratigraphisch als durch morphologischen Wechsel in der Geländeform zu erkennen (12). Im Mindelwall nördlich Unterweiler ist die Moräne flach auf Mindelschotter aufgeschoben, der sich in steilwandigen Abbrüchen nach Stein fortsetzt.

Die Grenze Mindel/Riß liegt zwischen den Höhen von Sigmaiers und Oberweiler, während nach Eberl $(1930,271)$ auch Sigmaiers noch einen Mindelwall darstellt.

Das tief eingeschnittene breite Tal der Óstliçhen Günz durchbricht bei Ronsberg die alt- und mittelpleistozänen Endmoränengürtel. Die äußersten Spuren des mindeleiszeitlichen Gletschers östlich des Tales sind sowohl morphologisch als auch stratigraphisch nördlich Neuenried und jenseits der Mindel bei Reichartsried festzustellen.

Der Randlagengürtel verschmälert sich von 3 auf $1 \mathrm{~km}$ vom Mindelquellgebiet gegen Osten bis Eggenthal, und besteht nunmehr aus 2-4 Wallzügen. Außer der markanten $20 \mathrm{~m}$ hohen Endmoräne der Holzheuer Höhe (EBERL 1930, 271) sind die übrigen zerschnittenen und verwaschenen Reste der mindeleiszeitlichen Randlagen sehr flach. Sie können deutlich von den großen äußersten Rißendmoränen bei Mindelberg, Beschaunen und Webams getrennt werden. Das tief eingeschnittene Mindeltal, das die Hauptabflußrinne 
des Rißgletschers bei Willofs-Gfäll gewesen ist, zerschneidet die Mindelrandlagen östlich Ronsberg in zwei separate Teile. Die Mindel/Riß-Grenze liegt zwischen Wolfs und Eglofs, wo in zwei Kiesgruben auf dem Rißschotter noch eisrandnahe Schottermoräne aufgeschlossen ist (13).

Am Westende der Holzheuer Höhe tritt die blockreiche Mindelmoräne unter einem Rißschotter zu Tage (14). Bei Sonderhof-Schönlings liegt die Grenze der Mindelmoräne zu den entsprechenden Fluvioglazialschottern. In der Grenzzone zwischen Mindel und Riß liegt nördlich Webams in einer Kiesgrube unter eisrandnaher Schottermoräne (Riß) verfestigte Mindelmoräne mit einer Blockschicht (15). Etwa $1 \mathrm{~km}$ südlich Bayersried ist ein verfestigter moränennaher Mindelschotter am Wegrand aufgeschlossen (16).

Westlich Eggenthal sind nur drei flachgewölbte Reste des mindeleiszeitlichen Endmoränengürtels erhalten. Am westlichen Steilhang des Mühlbachtales bei Eggenthal ist eine blockige Mindelmoräne zu beobachten (17).

Auf dem Hochgebiet von Irsee östlich Eggenthal zieht sich der zerschnittene mindeleiszeitliche Randlagengürtel von Schleifmühle und Haslach nach Oggenried und ist nachher westlich des Wertachtales nicht mehr zu erkennen. Die weiteren Mindelmoränen sind vom Rißgletscher überfahren und überdeckt worden. Die Grenze Mindel/Riß ist etwa durch Burgholz nach Oggenried zu ziehen. Óstlich Schleifmühle ist die Mindelmoräne am Weg bei Weilen aufgeschlossen (18). Westlich von Irsee liegen in einer Kiesgrube auf der Tertiärbasis bei $760 \mathrm{~m}$ ü. NN Mindelschotter und steinige Mindel-Blockmoräne (19).

\section{Endmoränen der Rißvereisung}

Auf die Mindeleiszeit folgte als vorletzte Kaltzeit die Rißeiszeit. Im Illergletschergebiet umfassen die rißeiszeitlichen Ablagerungen eine bis über $10 \mathrm{~km}$ breite Zone mit bis zu 15 Endmoränenwällen, die in mehrere Staffeln gegliedert werden können und die sich auch morphologisch voneinander unterscheiden. Letztere Randlagen sind im allgemeinen flacher als die mittleren. Die mittleren bestehen aus mehreren hohen und langen Moränenwällen. Die innersten wiederum sind etwas kleiner und liegen hart an der würmzeitlichen Vereisungsgrenze oder sind $z$. T. vom Würmgletscher überfahren worden. Die Rißvereisung ist etwa $1-4 \mathrm{~km}$ hinter der mindeleiszeitlichen Maximalausdehnung zurückgeblieben.

Unmittelbar östlich der heutigen Iller liegen die verschieden alten Endmoränen besonders dicht beieinander. Dieses Gebiet bildet eine Schlüsselstelle bei der Abtrennung der drei letzten Kaltzeiten. Südlich Grönenbach, zwischen Greit (Mindel) und Sommersberg (Riß), setzt ein tiefes, während der Rißeiszeit angelegtes Schmelzwassertal an, das sowohl die älteren Mindelmoränen als auch die Mindelschotter des Grönenbacher Feldes durchschneidet (Tafel I). Morphologisch sind die Rißmoränen bei Herbisried und Sommersberg aber nicht leicht von den Mindelmoränen abzutrennen. Der Würmgletscher scheint mit seinem äußersten Rande auf die Rißendmoränen bei Sachsenried und z. T. auch bei Sommersberg aufgefahren zu sein. Das jungpleistozäne Moränenmaterial zeigt die typischen frischen Formen. Dabei hat der jungpleistozäne Gletscherrand den Hauptrißwall bei Herbisried nicht mehr erreicht.

Penck \& Brückner (1909) und Schaefer (1951) halten alle Altmoränen in diesem Gebiet für mindeleiszeitlich und die Rißmoränen vom Würmgletscher überfahren. Nach SINN (1972, 121) sind die kleinkuppigen Rücken vom Sommersberg-Herbisried deutlich vom würmeiszeitlichen Material aufgebaut, wobei er den Wall bei Greit für rißeiszeitlich hält.

Die zahlreichen Rißendmoränen auf den Falkener und Böhener Riedeln sind im Durchschnitt größer und höher und bilden eine breitere Zone als die mindeleiszeitlichen 
Eisrandlagen. Besonders hoch sind die mittleren rißzeitlichen Randlagen im Schellenberger Wald $(877 \mathrm{~m})$, denn sie überragen deutlich die äußersten Rißmoränenwälle bei Oberwarlins, Osterwald $(846 \mathrm{~m})$ und Schilchern-Hinterhalde $(850 \mathrm{~m})$. Bei Reutacker und Todtenberg befinden sich die innersten Rißmoränenwälle. Der Todtenberger Moränenrücken ist vom Würmgletscher überfahren worden, was deutlich in der Kiesgrube im äußersten Jungmoränenwall auf dem Kamm von Todtenberg zu erkennen ist (20). SinN $(1972,121)$ vermutet in den Kuppen bei Schilchern und nördlich davon die äußere Randlage des Mindelgletschers, während die rißeiszeitlichen Altmoränen bei Bärenwies östlich Schrattenbach in Erscheinung treten. Bei Schellenberg hat sich in einem Aufschluß die frische Rißmoräne direkt auf dem Tertiär abgelagert (21).

Auf der östlichen Talseite der Westlichen Günz verbreitet sich die Zone der rißeiszeitlichen Gletscherrandlagen bis zu $7 \mathrm{~km}$. Die Maximalausdehnung des Rißgletschers ist auf der Linie Hinterschmalholz-Kuisler-Sigmaiers angezeigt. Im Süden ist der bis $883 \mathrm{~m}$ aufragende Rißmoränenrücken von Waitzenried ein Eisteiler gewesen, indem er den Würmgletscher in zwei separate Eiszungen geteilt hat (westliche und östliche Günztalzunge).

Die Ost-Fortsetzung der Hauptrißwälle im Schellenberger Wald bilden die markantesten rißeiszeitlichen Endmoränen im Arbeitsgebiet, nämlich der Simmerberg $(901 \mathrm{~m})$, der Ullenberg (875), der Hartmannsberg (884) und die Rücken bei Waitzenried (883) und Freien $(870 \mathrm{~m})$. Die bis $50 \mathrm{~m}$ über ihre Umgebung hinausragenden und über $1 \mathrm{~km}$ breiten Moränenrücken erheben sich annähernd $150 \mathrm{~m}$ über die tief eingeschnittenen Haupttäler der Westlichen und Ostlichen Günz und vertreten gleichzeitig die höchsten Eisrandlagen in Bereich des Illervorlandgletschers. Diese Höhenrücken zeugen von einer gewaltigen Auftürmungskraft des rißzeitlichen Illergletschers.

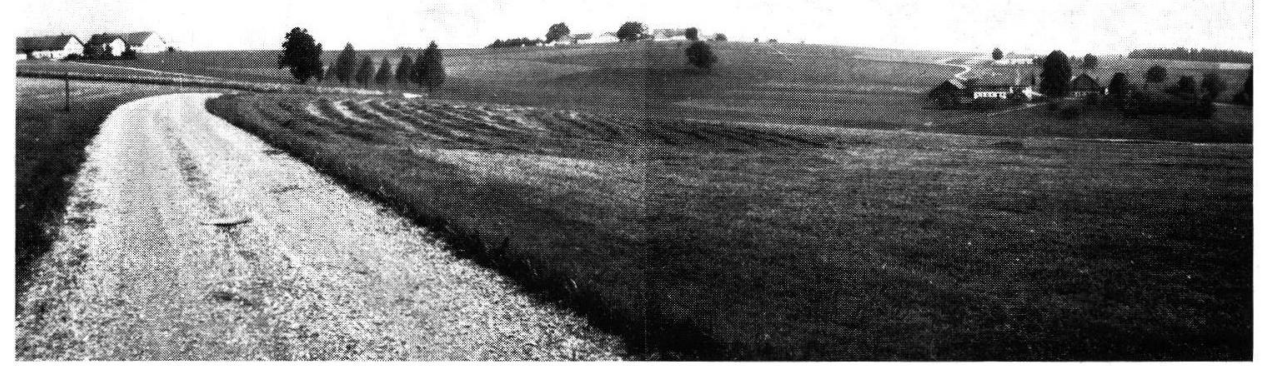

Abb. 3. Außere Rißendmoräne bei Hinterschmalholz. Photo: Glückert, Juni 1973.

Südlich Hinterschmalholz ist die blockreiche Rißmoräne auf verfestigtem Fluvioglazialschotter (Mindel ?) aufgeschoben und wird durch eine Schlifffläche getrennt (22) (Abb. 3). Am Ostende des Simmerbergs ist bei Eschers die großblockige Rißmoräne mit Blöcken bis zu $1 \mathrm{~m}$ Durchmesser aufgeschlossen (23). Bei Berg südlich Freien liegt die Rißmoräne am Wegrande auf einer verfestigten Schotterunterlage (24). Ein Stück abwärts ist in einer großen Kiesgrube unter z. T. lockerer Riß-Schottermoräne ein stärker verfestigter Schotter zu erkennen (25).

Jenseits der Óstlichen Günz ist der Rißmoränengürtel am breitesten, indem die Endmoränenzone eine Breite bis zu $11 \mathrm{~km}$ erreicht. Die Scheitel der größten Rücken bei Mittelberg-Upratsberg (893 m), Heimenhalden (899), Ebersbach (878), Burg (870), Wolfahrtsberg (868), Gfäll (840) und Willofs $(838 \mathrm{~m})$ erheben sich als markante rißzeitliche Eisrandlagen etwa $150 \mathrm{~m}$ über das Tal der Ostlichen Günz. 
Die Grenze Mindel/Riß liegt zwischen den äußersten hohen Rißendmoränen bei Mindelberg-Beschaunen und den flachen innersten Mindelmoränen bei Birkach-Bihls-Stehlings. Der $886 \mathrm{~m}$ hohe Schlegels-Berg südlich Günzach hat als eine riesige Barriere den vorstoßenden Würmgletscher in zwei Zungen geteilt (Tafel I).

Die innersten und mittleren, langgestreckten Rißrandlagen bei Mittelberg, Upratsberg und Heimenhalden sind so hoch gewesen, daß die Schmelzwasserentwässerung in peripheren Rinnen nach beiden Seiten hin erfolgt ist. Nördlich Ebersbach sind mehrere Randlagen aber auch durch zentrifugale Erosionstäler zerschnitten. Die letztgenannten Rinnen mit dem Röhrwanger Mühlbach und dem Mindel-Ursprungstal bilden hier die bedeutendsten Abflußkanäle des Rißgletschers. Die erstere Rinne beginnt südlich Ebersbach, die letztere östlich Willofs.

Ớstlich von Günzach ist die Rißendmoräne bei Marxer aufgeschlossen. Unter einer $2 \mathrm{~m}$ Deckschicht von grobsteiniger Riß-Schottermoräne kommen 3-4 m z. T. verfestigter, und zuunterst etwa $8 \mathrm{~m}$ lockerer, kiesiger Vorstoßschotter zum Vorschein (26). In der neuen Kiesgrube beim Johanniskeller östlich Obergünzburg liegt unter $3 \mathrm{~m}$ Rißmoräne im schräggeschichteten Vorstoßschotter eine verfestigte Sandlinse (27). Bei Burgstall am SE-Ende des Wolfahrtsberges ist die grobblockige Rißmoräne über Vorstoßschotter aufgeschlossen (28) (Abb. 4).

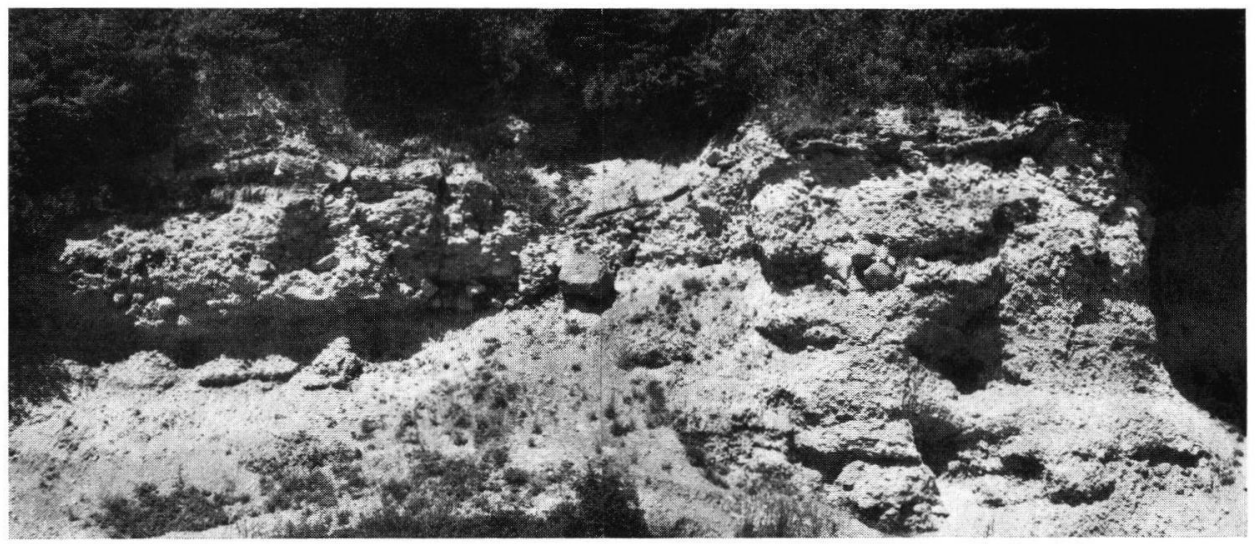

Abb. 4. Grobblockige Rißmoräne in der Kiesgrube bei Burgstall nördlich Obergünzburg (Aufschluß Nr. 28, Abb. 2). Photo: Glückert, Juni 1973.

In der Teufelsküche liegt unter der blockigen Rißmoräne im Schotter noch eine ältere Blockschicht (Mindel ?) (29). Óstlich Eglofs ist die flache Rißmoräne auf geschichtetem Mindelschotter geglitten (30). Bei Wolfs östlich Ronsberg ist die Rißmoräne durch eine Schlifffläche von dem liegenden Schotter getrennt (13). Bei Mautis war in einer neuangelegten Silogrube steinige Rißmoräne mit kantigen Blöcken bis zu 0,5 m Durchmesser zu sehen (31).

Jenseits des Mühlbachtales wird der Randlagengürtel der Rißkaltzeit immer schmäler. Er zieht als 3-5 km breite Zone von der Gegend Salenwang-Friesenried-Blöcktach durch den Königsberger Forst nach Großkemnat und Kleinkemnat, wo er nach Norden umbiegt, um hinter Irsee völlig zu verschwinden. Die größten Rißendmoränen sind der Schneckenberg im Eichwald und die hohen Rücken bei Kleinkemnat südlich Irsee. Bei Großkemnat ist die blockreiche Rißmoräne am Wegrande aufgeschlossen (32) (Tafel I). 


\section{Ergebnisse}

Die mindel- und rißeiszeitlichen Endmoränen des Illervorlandgletschers liegen auf den hochgelegenen Schotterriedeln der Günz- bzw. Mindeleiszeit. Sie wurden im Allgäu im Bereich zwischen Iller und Wertach vom Verfasser geologisch kartiert und voneinander getrennt.

Seine größte Ausdehnung im Alpenvorland hatte der Illergletscher in der Mindeleiszeit. Hier ist die Ausbreitung des Mindelmoränenkranzes weder von den Riß- noch Würmmoränen wieder erreicht worden. Der äußere $1-4 \mathrm{~km}$ schmale Altmoränengürtel gehört der Mindeleiszeit, die innere bis $11 \mathrm{~km}$ breite Zone der Rißeiszeit an.

Die Vereisungsgrenze der Mindeleiszeit ist etwas nördlicher zu ziehen als man bisher angenommen hat. Auch die Grenze Mindel/Riß weicht etwas von den Auffassungen von Penck \& Brückner (1909), Eberl (1930), Schaefer (1953 b) und Sinn (1972) sowie der Geologischen Karte von Baden-Württemberg $(1: 200000)$ ab.

Der Verlauf der zentrifugal oder peripher verlaufenden mindel- und rißeiszeitlichen Entwässerungsrinnen kann hier für die Untergliederung der Altendmoränengebiete herangezogen werden. Die flachen Mindelrandlagen sind von den zentrifugal abziehenden äußersten rißeiszeitlichen Entwässerungsrinnen in Hügelreste zerschnitten worden. Während der Ausbildung der mittleren und innersten Rißrandlagen wurde der Gletscher vorwiegend durch peripher angelegte, vom Verlauf der querliegenden Rißwälle bestimmten Schmelzwassertäler nach beiden Seiten hin entwässert.

Die würmeiszeitlichen Iller- und Wertachgletscher sind im Arbeitsgebiet in fünf kleine Zungen, nämlich mit der Dietmannsrieder, Untrasrieder, Obergünzburger, Friesenrieder und Kaufbeurener Zunge bis in den Randbereich der Rißmoränen vorgestoßen. Die beiden letz.tgenannten gehören dem Wertachgletscher an, der sich ostwärts an den Illergletscher anschließt (Abb. 2).

Die frischen, unruhigen und vielfach kleinen Formen der Jungmoränen mit Moorböden und Söllen sind deutlich von den breiten, flachen und tiefer verwitterten Mindelund Riß-Moränen außerhalb der Würmrandlagen zu unterscheiden. Die äußersten Jungendmoränen bilden mehrere bogenförmige Wallreihen, deren Verlauf von zahlreichen Schmelzwasserrinnen unterbrochen ist.

\section{Literaturnachweis}

Bayerisches Geologisches Landesamt (1964): Erläuterung zur Geologischen Karte von Bayern $1: 500000$, 2. Aufl., 344 S. und Karte, München.

EBerL, Bartholomäus (1930): Die Eiszeitenfolge im nördlichen Alpenvorlande. Ihr Ablauf, ihre Chronologie auf Grund der Aufnahmen im Bereich des Lech- und Illergletschers. 427 S., Augsburg.

EIChleR, Horst (1970 a): Das präwürmzeitliche Pleistozän zwischen Riß und oberer Rottum. - Heidelberger Geogr. Arb. 30, 128 S., Heidelberg.

- (1970 b): Zur stratigraphischen Definition des Begriffes „Günz“ im östlichen RheingletscherGebiet. - N. Jb. Geol. Paläont. Mh. 1970, 414-417, Stuttgart.

GlüCKert, Gunnar (1974): On Pleistocene glaciations in the German Alpine foreland. - Bull. geol. Soc. Finland 46, Helsinki (im Druck).

German, Rüdiger (1960): Die Würmvereisung im Rhein- und Illergletscher zwischen Federseebecken und Günztal. - Geologica Bavarica 43, 3-73, München.

- (1962): Zur Geologie des Lechvorlandgletschers. - Jber. u. Mitt. oberrh. geol. Ver. N.F. 44, 61-83, Stuttgart.

Graul, Hans (1953): Zur Gliederung der Würmeiszeit im Illergebiet. - Geologica Bavarica 18, 13-48, München.

- (1962): Eine Revision der pleistozänen Stratigraphie des schwäbischen Alpenvorlandes. Petermanns Geogr. Mitt. 106, 253-271, Gotha. 
Graul, Hans (1968): Führer zur zweitägigen Exkursion im nördlichen Rheingletschergebiet (DEUQUA-Tagung 1968). - Heidelberger Geogr. Arb. 20, 31-78, Heidelberg.

Mader, Matthias (1971): Das Quartär zwischen Adelegg und Hochgelände (Bildungsweise und Stratigraphie). - Jh. Ges. Naturkunde Württemberg 126, 178-205, Stuttgart.

Penck, Albrecht \& Brǘckner, Eduard (1909): Die Alpen im Eiszeitalter I. Die Eiszeiten in den nördlichen Ostalpen, 393 S., Leipzig.

Schaefer, Ingo (1951): Quartärgeologische Exkursion durch die Riß-Lechplatte. - Geologica Bavarica 6, 98-114, München.

- (1953 a): Die donaueiszeitlichen Ablagerungen an der Lech und Wertach. - Geologica Bavarica 19, 13-64, München.

- (1953 b): Zur Gliederung der Würmeiszeit im Illergebiet. Stellungnahme zu den Ausführungen H. Graul's. - Geologica Bavarica 18, 49-112, München.

- (1973): Das Grönenbacher Feld. Ein Beispiel für Wandel und Fortschritt der Eiszeitforschung seit Albrecht Penck. - Eiszeitalter u. Gegenwart 23/24, 168-200, Ohringen.

Sinn, Peter (1971): Zur Ausdehnung der Donau-Vergletscherung im schwäbischen Alpenvorland. - Eiszeitalter u. Gegenwart 22, 188-191, OOhringen.

- (1972): Zur Stratigraphie und Paläogeographie des Präwürm im mittleren und südlichen Illergletscher-Vorland. - Heidelberger Geogr. Arb. 37, 153 S., Heidelberg.

Kartengrund lagen :

Topographische Karte 1:25000:

8027 Memmingen

8028 Markt Rettenbach

8127 Grönenbach

8128 Obergünzburg;

Topographische Karte 1:50 000:

L 8126 Memmingen

L 8128 Kaufbeuren.

Geologische Ubersichtskarte von Baden-Württemberg, Blatt 4, 3. Aufl., $1: 200$ 000, Stuttgart 1962.

Geologische Karte von Bayern, 2. Aufl., 1 : 500 000, München 1964.

Manuskript eingeg. 11. 1. 1974.

Anschrift des Verf.: Dr. G. Glückert, Institut für Quartärgeologie der Universität Turku, 20500 Turku 50, Finnland. 